\title{
OBSERVATIONS OF THE INFLUENCE OF CHONDROITIN SULPHATE ON THE RATE OF BONE REPAIR
}

\author{
Martin Burger*, Burton S. Sherman and Albert E. Sobel \\ New York, United States of America \\ From the Department of Biochemistry, the Jewish Hospital of Brooklyn, New York
}

This paper presents a study of the effect of chondroitin sulphate on the rate of bone repair promoted by demineralised bone, reconstituted acid-soluble collagen, and gelatin in the form of Gelfoam. $t$ The index employed was the rate of bone repair in a standard defect produced in the calvaria of rats.

These investigations are an extension of our earlier studies in which we observed that, under certain conditions, chondroitin sulphate would restore the mineralising properties of demineralised bone (predominantly acid-insoluble collagen) in vitro with inorganic media, and in vivo when transplanted under the skin of rats (Burger, Lavine, Deane and Sobel 1957; Sobel, Burger and Deane 1957; Sobel, Burger and Lavine 1960; Sobel, Burger and Nobel 1960, Sobel 1961).

\section{MATERIALS AND METHODS}

The animals used in these studies were an inbred strain of Wistar albino rats raised on the stock diet used by Bills, Honeywell, Wirick and Nussmeier (1931). At weaning (twenty-one to twenty-three days of age), those animals selected as hosts (receiving implant materials) were continued on the stock diet. The other animals, whose skull and tibial bones were used as implants, were placed on a rachitogenic diet (Burger, Lavine, Deane and Sobel 1957), since it was found that bone from rachitic animals could be more readily demineralised. In addition, implants were obtained from rats on the normal diet.

Implant materials. Demineralised bones-A 4 per cent disodium ethylenediamine tetra-acetic acid solution (EDTA), adjusted to $\mathrm{pH} 4$ with acetic acid, was used to demineralise freshly excised and cleaned tibiae and calvaria of rachitic rats. The demineralisation was carried out for forty-eight to seventy-two hours at room temperature with frequent shaking by hand during the course of the day. The decalcifying solution was changed every morning and evening until demineralisation was complete, as shown by a negative test for calcium on addition of saturated ammonium oxalate to a few drops of the supernatant fluid. An aliquot sample of the ash of a bone which was demineralised at the same time as the others, but not used as an implant, also gave a negative test for calcium. The material was thoroughly washed five times with 0.04 per cent acetic acid solution at pH 4 to remove the EDTA. The material was then minced with scissors to fine particles and subsequently divided into two portions. One portion was placed in a sterile vial containing 10 millilitres of 0.04 per cent acetic acid solution, and the other portion was placed in a sterile vial containing 10 millilitres of a 1 per cent chondroitin sulphate $\ddagger$ solution at $\mathrm{pH} 4$. (The latter was prepared by dissolving 500 milligrams of the mucopolysaccharide powder in 40 millilitres of 0.04 per cent acetic acid, adjusting the pH to 4 with a few drops of concentrated acetic acid, and making the solution up to a volume of 50 millilitres with 0.04 per cent acetic acid. The solution was centrifuged at 13,000 revolutions per minute in a Servall angle centrifuge at 5 degrees Centigrade. The slightly turbid supernatant fluid was decanted from any sediment that may have separated out, and this fluid was used as the 1 per cent chondroitin sulphate solution.) The demineralised bone particles were allowed to stand overnight in the vial of appropriate solution at 5 degrees Centigrade. The mixture was subjected to high speed centrifugation and the supernatant discarded. The treated demineralised bone fragments thus recovered were used as implants. Fresh homogenous bone-The calvaria and tibial shafts of rachitic or normal rats were excised and cleaned free of soft tissue. Each of the bone tissues was minced with scissors to fine particles. During the mincing process it was necessary to add a few drops of sterile, 0.85 per cent saline solution to keep the tissues moist. The minced tissues were stored in sterile 10-millilitre screw-capped glass vials.

\footnotetext{
* Deceased.
}

† Gelfoam-absorbable hemostatic gelatin, Upjohn Co., Kalamazoo, Michigan, United States of America.

‡ The chondroitin sulphate was obtained from Dr Erik Jorpes of the Karolinska Institute, Stockholm, Sweden, and is composed primarily of chondroitin sulphate A. The chondroitin sulphate was analysed by Dr Karl Meyer of the Department of Biochemistry, Columbia University, College of Physicians and Surgeons.

vol. 44 B, NO. 3, AUGUST 1962 
Precipitated acid-soluble collagen-Acetic acid-soluble collagen was prepared from rat tail tendon as described in a previous report (Sobel and Burger 1954). The collagen solution (at pH 4) was divided into two portions. One portion was precipitated with 1 per cent chondroitin sulphate solution, and the other portion was precipitated by salting out with sodium chloride $(\mathrm{NaCl})$ crystals to produce a final concentration of 1 per cent $\mathrm{NaCl}$. The $\mathrm{NaCl}$ precipitated solutions were allowed to stand overnight at 5 degrees Centigrade and the precipitates were separated in a refrigerated angle centrifuge. The clear supernatant fluids were discarded and the precipitates were washed once with ice-cold sterile saline. The latter was allowed to drain off, leaving a moist precipitate having a consistency of soft dough which could be easily handled with a blunt dissecting probe.

Gelfoam-Sterile Gelfoam sponges, $20 \times 60 \times 7$ millimetres, were cut into small cubes approximately 2 to 3 millimetres long. One portion was placed in a vial and soaked for eighteen hours at 5 degrees Centigrade in dilute 0.04 per cent acetic acid at $\mathrm{pH} 4$, and another portion in a second vial was soaked for eighteen hours at 5 degrees Centigrade in 1 per cent chondroitin sulphate solution at pH 4 . The following day the solutions were decanted and the sponges were squeezed to eliminate most of the absorbed solutions. The sponges were washed once with sterile saline, the solution was decanted and the sponges were again squeezed to eliminate most of the absorbed saline. The soaking, decanting, washing and squeezing processes were performed in the same vials that contained the original pieces of the cut Gelfoam.

Surgical procedures-The animals that received the implants were from six to eight weeks old at the time of operation. Under ether anaesthesia an incision was made across the scalp just anterior, and extending, to each ear. The skull was exposed by retracting the scalp with forceps. Defects approximately 2 millimetres in diameter were drilled through both tables and dura of the parietal bones on either side of the sagittal suture, by use of a portable dental drill with a contra-angle handpiece and a Number 8 round, diamond stone burr. The defects were made by applying the burr to the bone intermittently and with slight pressure, to avoid excessive heating of the bone, until the first sign of bleeding occurred in the defect. At this point the drilling was continued with more caution to avoid damage to the brain. After the hole had been drilled the area of the wound was bathed with a stream of sterile saline to wash away small particles of bone and other extraneous matter. The implant material was placed in the defects by use of a blunt-end dissecting probe. The cut edges of the scalp were then approximated and sutured together with silk thread. The animals regained consciousness, and became active a few minutes after the surgical procedures.

Defects which were drilled through one side of the rat parietal bone, and which were left implantfree, served as controls for the experimentally treated defects. In many rats one side of the skull was used as an implant-free control for the other side, which was experimentally treated with an implant. In others, each side of the skull received a different type of implant material.

All equipment was sterilised in 70 per cent ethanol. No antibiotics or other medications were administered to the animals after operation. At no time was infection encountered.

Typical experimental procedure - In any single experiment several litters of rats six to eight weeks old were combined so that from nine to eighteen animals were available for operation. The animals were then subjected to surgical and implantation procedures described previously. One or two animals were killed each week for a period of nine weeks. The calvaria of these animals were excised, and all soft adhering tissue was carefully dissected away in such a manner that the implant material in the parietal bones was not disturbed. The implant areas were examined with a needle point probe to determine the degree of hardness of the area. Radiographs were obtained of each calvarium by placing it on a film holder containing a $5 \times 7$ inch sheet of Kodak Contrast Process Ortho film. The x-ray machine was placed so that the calvaria were twelve inches from the tube. An exposure time of fifteen seconds was used at eight kilovolts and thirty milli-amps. No filters were used. The calvaria were then placed in 10 per cent neutral formalin for two to three days. The specimens were then decalcified by use of 5 per cent formic acid for three days. After being washed overnight in water and then dehydrated the specimens were vacuum-infiltrated and embedded in paraffin. The specimens were cut in both sagittal and coronal planes. Sections five $\mu$ in thickness were stained routinely with Lillie's haematoxylin and eosin.

\section{PRELIMINARY STUDIES}

Initially our studies were concerned with the healing of experimentally produced skull defects as shown by radiographs and naked-eye inspection with needle point probe to test 
the hardness of the implant area. In these studies 145 rats were examined at weekly intervals after implantation. The materials used as implants were demineralised bone and demineralised bone treated with 1 per cent chondroitin sulphate. It was noted (with few exceptions) that, radiographically, almost complete healing occurred nine weeks following operation in the case of demineralised bone, while only six weeks were necessary in the case of demineralised bone treated with 1 per cent chondroitin sulphate. The studies were performed in order to gain experience of the relative ability of these materials to aid in bone repair. Since no histological examinations of these specimens were done the results will not be fully discussed.

\section{DEFINITIVE STUDIES}

Once we had made ourselves familiar with the radiographic possibilities of demineralised bone-with and without chondroitin sulphate treatment - a more critical survey was undertaken in which histological as well as radiological studies were made at weekly intervals. The materials examined for their ability to aid in bone repair included: 1) EDTA-demineralised bone. 2) EDTA-demineralised bone treated with 1 per cent chondroitin sulphate. 3) Acidsoluble rat tail tendon collagen reconstituted with 1 per cent chondroitin sulphate. 4) Acidsoluble rat tail tendon collagen reconstituted with 1 per cent $\mathrm{NaCl}$. 5) Gelfoam. 6) Gelfoam treated with 1 per cent chondroitin sulphate. 7) Fresh homogenous bone from normal rats. 8) Fresh homogenous bone from rachitic rats.

A total of 497 rats were used in forty-three separate experimental trials in these studies. They were each examined histologically and radiologically.

The experiments may be divided arbitrarily into four groups. However, these groups should not be considered chronologically consecutive because the individual experiments in each group were repeated many times from 1956 to 1960.

Group I-Demineralised bone and demineralised bone-chondroitin sulphate-The primary purpose of the experiments in this group was to compare demineralised bone and demineralised bone treated with chondroitin sulphate in their abilities to aid in bone repair. As can be seen from Table I, demineralised bone was directly compared with demineralised bone-chondroitin sulphate in a total of 133 rats in ten separate experiments. Additional experiments were performed in which one substance was placed in one defect, whereas the defect on the opposite side was left implant-free. Table I shows that demineralised bone was compared with an untreated control defect in a total of forty-four animals on three separate occasions. Demineralised bone treated with chondroitin sulphate was compared with untreated control defects in a total of forty-three animals in three separate experiments. The animals in these groups were killed weekly for a period of nine weeks following operation.

Group II-Collagen $\mathrm{NaCl}$ and collagen-chondroitin sulphate-Acid-soluble collagen reconstituted with chondroitin sulphate was prepared and used as an implant material. For comparison, acid-soluble collagen reconstituted with $\mathrm{NaCl}$ was placed in the defect on the opposite side in the same animal. From Table $I$ it may be seen that a total of twenty-nine animals in three separate experiments were treated in this manner. These materials were also tested independently of each other. Thus, collagen-chondroitin sulphate was compared with untreated control defects in a total of twenty-eight animals on three different occasions and collagen- $\mathrm{NaCl}$ was tested against untreated control defects in a total of twenty-eight rats in three separate experiments. The animals in this group were killed weekly for a period of eight weeks following operation. Group III-Gelfoam and Gelfoam-chondroitin sulphate-In this group twenty-eight animals in three separate experiments were implanted on one side with Gelfoam and on the other side with Gelfoam-chondroitin sulphate (Table I). In addition, Gelfoam was compared with untreated controls in twenty-one rats on two separate occasions. Gelfoam-chondroitin sulphate was compared with untreated control defects in twenty-one rats in two different experiments. The animals in this group were killed weekly for a period of seven weeks after operation.

vol. 44 B, No. 3, AUGUST 1962 
TABLE I

Distribution of Animals in Experimental Groups

\begin{tabular}{|c|c|c|c|c|c|c|c|c|c|c|c|c|}
\hline \multicolumn{2}{|c|}{ Type of implant in skull defects } & \multirow[t]{2}{*}{$\begin{array}{l}\text { Number of } \\
\text { experiments }\end{array}$} & \multicolumn{8}{|c|}{$\begin{array}{c}\text { Total number of animals killed } \\
\text { each week after operation } \\
\text { Weeks after operation }\end{array}$} & \multirow[b]{2}{*}{9} & \multirow[t]{2}{*}{ Total } \\
\hline Kignt side & Leit siae & & 1 & 2 & 3 & 4 & 5 & 6 & 7 & 8 & & \\
\hline $\begin{array}{l}\text { Group I } \\
\text { Demineralised bone } \\
\text { Untreated control } \\
\text { Untreated control }\end{array}$ & $\begin{array}{l}\text { Demineralised bone- } \\
\text { chondroitin sulphate } \\
\text { Demineralised bone } \\
\text { Demineralised bone- } \\
\text { chondroitin sulphate }\end{array}$ & $\begin{array}{r}10 \\
3\end{array}$ & $\begin{array}{r}13 \\
4\end{array}$ & $\begin{array}{r}15 \\
5\end{array}$ & $\begin{array}{r}14 \\
5\end{array}$ & $\begin{array}{r}16 \\
5\end{array}$ & $\begin{array}{r}15 \\
5\end{array}$ & $\begin{array}{r}15 \\
5\end{array}$ & $\begin{array}{r}15 \\
5\end{array}$ & $\begin{array}{r}16 \\
5\end{array}$ & $\begin{array}{r}14 \\
5\end{array}$ & $\begin{array}{r}133 \\
44\end{array}$ \\
\hline $\begin{array}{l}\text { Group II } \\
\text { Collagen-sodium } \\
\text { chloride } \\
\text { Untreated control } \\
\text { Untreated control }\end{array}$ & $\begin{array}{l}\text { Collagen-chondroitin } \\
\text { sulphate } \\
\text { Collagen-chondroitin } \\
\text { sulphate } \\
\text { Collagen-sodium } \\
\text { chloride }\end{array}$ & 3 & 3 & 3 & 4 & 3 & 3 & 4 & 4 & 4 & & 28 \\
\hline $\begin{array}{l}\text { Group III } \\
\text { Gelfoam } \\
\text { Untreated control } \\
\text { Untreated control }\end{array}$ & $\begin{array}{l}\text { Gelfoam-chondroitin } \\
\text { sulphate } \\
\text { Gelfoam. } \\
\text { Gelfoam-chondroitin } \\
\text { sulphate }\end{array}$ & $\begin{array}{l}3 \\
2\end{array}$ & $\begin{array}{l}4 \\
3\end{array}$ & $\begin{array}{l}4 \\
3\end{array}$ & $\begin{array}{l}4 \\
3\end{array}$ & $\begin{array}{l}4 \\
3\end{array}$ & $\begin{array}{l}4 \\
3\end{array}$ & $\begin{array}{l}4 \\
3\end{array}$ & $\begin{array}{l}4 \\
3\end{array}$ & & & $\begin{array}{l}28 \\
21 \\
21\end{array}$ \\
\hline $\begin{array}{l}\text { Group IV } \\
\text { Demineralised bone } \\
\text { Demineralised bone } \\
\text { Demineralised bone- } \\
\text { chondroitin sulphate }\end{array}$ & $\begin{array}{l}\text { Fresh rachitic homo- } \\
\text { genous bone } \\
\text { Fresh normal homo- } \\
\text { genous bone } \\
\text { Fresh normal homo- } \\
\text { genous bone. }\end{array}$ & 5 & 8 & 9 & 4 & 8 & 9 & 9 & 3 & 6 & 6 & $\begin{array}{l}70 \\
30\end{array}$ \\
\hline
\end{tabular}

Group IV-Fresh rachitic homogenous bone, fresh normal homogenous bone, demineralised bone and demineralised bone-chondroitin sulphate-In these experiments comparisons were made among different types of fresh homogenous bone and demineralised bone with respect to their abilities in repairing the skull defects. Table I demonstrates that fresh rachitic homogenous bone and demineralised bone were implanted in skull defects in seventy animals in five separate experiments. Fresh homogenous bone was compared with demineralised bone in thirty rats in three experiments. Fresh normal homogenous bone and demineralised bone-chondroitin sulphate were compared in twenty-two animals on three separate occasions. The animals in this group were killed weekly for a period of nine weeks after operation.

\section{OBSERVATIONS}

A total of 994 separate observations were made both histologically and radiologically in these studies. The distribution of these observations according to the type of implant used is shown in Table II.

The relative performance of the implant materials used in these studies on the rate of healing of the bony calvarial defects is illustrated in Table III. The degree of healing is arbitrarily graded from 0 (no healing) to +++++ (the most repair), based on histological examination of fixed material. The method of grading is shown at the bottom of Table III.

Some degree of healing was seen at the end of the experimental period in all instances, although this healing was least $(+)$ in the controls and in the Gelfoam-implanted defects. 
TABLE II

Number of Skull Defects Examined Histologically and Radiographically

\begin{tabular}{|c|c|c|c|c|c|c|c|c|c|}
\hline \multirow[b]{2}{*}{$\begin{array}{c}\text { Weeks } \\
\text { after } \\
\text { operation }\end{array}$} & \multicolumn{9}{|c|}{ Type of implant material } \\
\hline & $\begin{array}{l}\text { Without } \\
\text { implant } \\
\text { (control) }\end{array}$ & $\begin{array}{l}\text { Collagen- } \\
\text { sodium } \\
\text { chloride }\end{array}$ & $\begin{array}{c}\text { Collagen- } \\
\text { chondroitin } \\
\text { sulphate }\end{array}$ & $\begin{array}{l}\text { Demineral- } \\
\text { ised bone }\end{array}$ & $\begin{array}{l}\text { Demineral- } \\
\text { ised bone- } \\
\text { chondroitin } \\
\text { sulphate }\end{array}$ & $\begin{array}{c}\text { Fresh } \\
\text { normal } \\
\text { homogenous } \\
\text { bone }\end{array}$ & $\begin{array}{c}\text { Fresh } \\
\text { rachitic } \\
\text { somogenous } \\
\text { bone }\end{array}$ & Gelfoam & $\begin{array}{l}\text { Gelfoam- } \\
\text { chondroitin } \\
\text { sulphate }\end{array}$ \\
\hline 1 & 19 & 6 & 5 & 28 & 20 & 6 & 8 & 7 & 7 \\
\hline 2 & 22 & 6 & 7 & 33 & 22 & 7 & 9 & 7 & 7 \\
\hline 3 & 23 & 8 & 7 & 31 & 21 & 7 & 9 & 7 & 7 \\
\hline 4 & 24 & 6 & 8 & 32 & 24 & 6 & 8 & 7 & 7 \\
\hline 5 & 22 & 7 & 7 & 31 & 22 & 6 & 9 & 7 & 7 \\
\hline 6 & 25 & 8 & 9 & 33 & 23 & 7 & 9 & 7 & 7 \\
\hline 7 & 24 & 8 & 8 & 29 & 22 & 5 & 6 & 7 & 7 \\
\hline 8 & 20 & 8 & 6 & 30 & 22 & 4 & 6 & - & - \\
\hline 9 & 10 & - & - & 28 & 20 & 4 & 6 & - & - \\
\hline Total & 189 & 57 & 57 & 275 & 196 & 52 & 70 & 49 & 49 \\
\hline
\end{tabular}

Both histological and radiographical observations were made for each implant material examined.

TABLE III

Relative Performance of Implant Materials in Healing of Standard Bone Defects in Rat Calvaria

\begin{tabular}{|c|c|c|c|c|c|c|c|}
\hline $\begin{array}{l}\text { Weeks after } \\
\text { operation }\end{array}$ & $\begin{array}{l}\text { Without } \\
\text { implant } \\
\text { (control) }\end{array}$ & Gelfoam & $\begin{array}{l}\text { Gelfoam with } \\
1 \text { per cent } \\
\text { chondroitin } \\
\text { sulphate }\end{array}$ & $\begin{array}{c}\text { Demineralised } \\
\text { bone or fresh } \\
\text { homogenous } \\
\text { bone }\end{array}$ & $\begin{array}{l}\text { Demineralised } \\
\text { bone with } \\
1 \text { per cent } \\
\text { chondroitin } \\
\text { sulphate }\end{array}$ & $\begin{array}{l}\text { Collagen- } \\
\text { sodium } \\
\text { chloride }\end{array}$ & $\begin{array}{l}\text { Collagen- } \\
\text { chondroitin } \\
\text { sulphate }\end{array}$ \\
\hline 1 & 0 & 0 & 0 & + & + & 0 & 0 \\
\hline 2 & 0 & 0 & 0 & + & + & 0 & + \\
\hline 3 & 0 & 0 & 0 & + & ++ & 0 & ++ \\
\hline 4 & 0 & 0 & 0 & ++ & +++ & 0 & ++ \\
\hline 5 & 0 & 0 & 0 & ++ & $++t$ & 0 & $+t+$ \\
\hline 6 & 0 & 0 & + & +++ & +++++ & + & $+t+$ \\
\hline 7 & 0 & + & ++ & $++t$ & $+t+t+$ & + & +++ \\
\hline 8 & 0 & & & +++ & $+t+t+$ & ++ & $++t+t$ \\
\hline 9 & $\therefore$ & & & $+++t$ & $++t+$ & & \\
\hline
\end{tabular}

The degree of healing is graded arbitrarily from 0 (no healing) to +++++ (greatest repair) based on histological examination of fixed material.

0 No healing.

+ Less than 20 per cent of defect area repaired. (Usually a trace only.)

L + Between 20 and 40 per cent of defect area repaired.

- + + + Between 40 and 60 per cent of defect area repaired.

++++ Between 60 and 80 per cent of defect area repaired.

Between 80 and 100 per cent of defect area repaired. (Usually complete repair.)

vol. 44 B, NO. 3, AUGUST 1962 
Demineralised bone-chondroitin sulphate appeared to accelerate the process of bone repair when compared with untreated demineralised bone. Six weeks were required to achieve the most healing $(+++++)$ in the former, while nine weeks were necessary for the latter. Out of a total of 196 observations made on demineralised bone-chondroitin sulphate, in only two had the most healing occurred at seven weeks, and in only one at five weeks. With untreated demineralised bone, only twice out of 275 observations was there the most healing at eight weeks, while three defects were not fully healed at nine weeks.

Fresh homogenous normal and rachitic bone acted in the same way as untreated demineralised bone, that is, nine weeks were needed for the most repair $(+++++)$. Out of 122 observations made none showed the most repair earlier than nine weeks, while two were not fully healed at nine weeks.

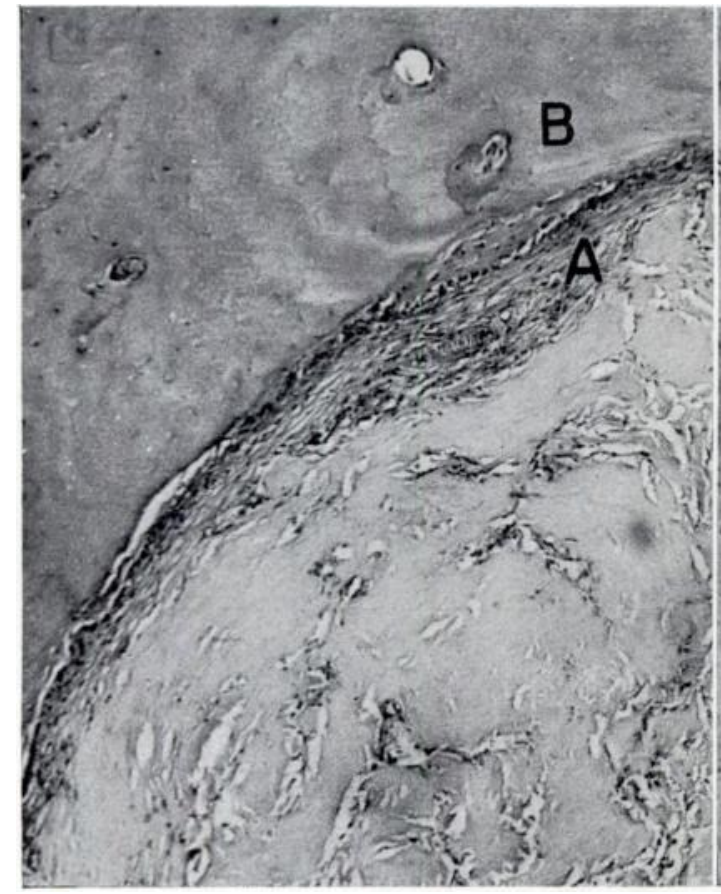

FiG. 1

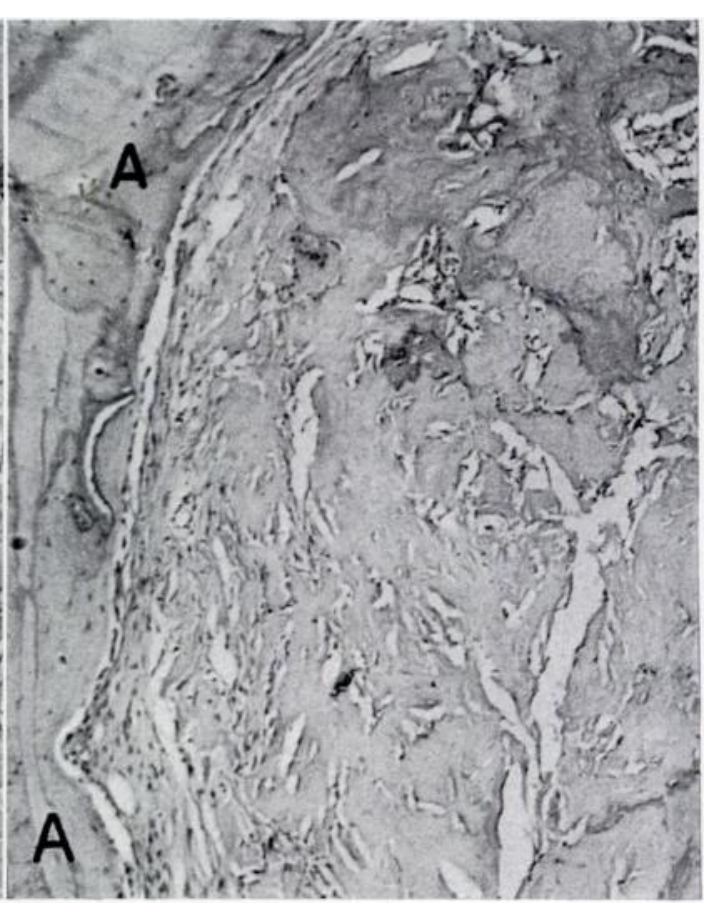

FIG. 2

Figure 1-Control defect after nine weeks-no implant. The area of the defect is filled with a mass of fibrous connective tissue. A very small area of new bone formation (A) may be seen growing from the margin of the host bone (B). (Haematoxylin and eosin, $\times 100$.) Figure $2-$ Gelfoam-implanted defect after seven weeks. Little if any formation of new bone is observed. The margin of the host bone is at A. (Haematoxylin and eosin, $\times 100$.)

In all instances collagen-chondroitin sulphate-implanted defects showed the most healing $(+++++)$ eight weeks after operation, while all collagen-NaCl-implanted defects showed only partial healing $(++)$ at this time.

Gelfoam treated with chondroitin sulphate showed partial healing of the defect after seven weeks $(++)$. Defects implanted with Gelfoam alone showed only slight healing $(+)$ at this time.

From this data, it may be seen that the implant substance which best effected rapid and complete repair of the calvarial defect was demineralised bone treated with 1 per cent chondroitin sulphate.

A more detailed description of the healing process with each of the implant materials follows. 


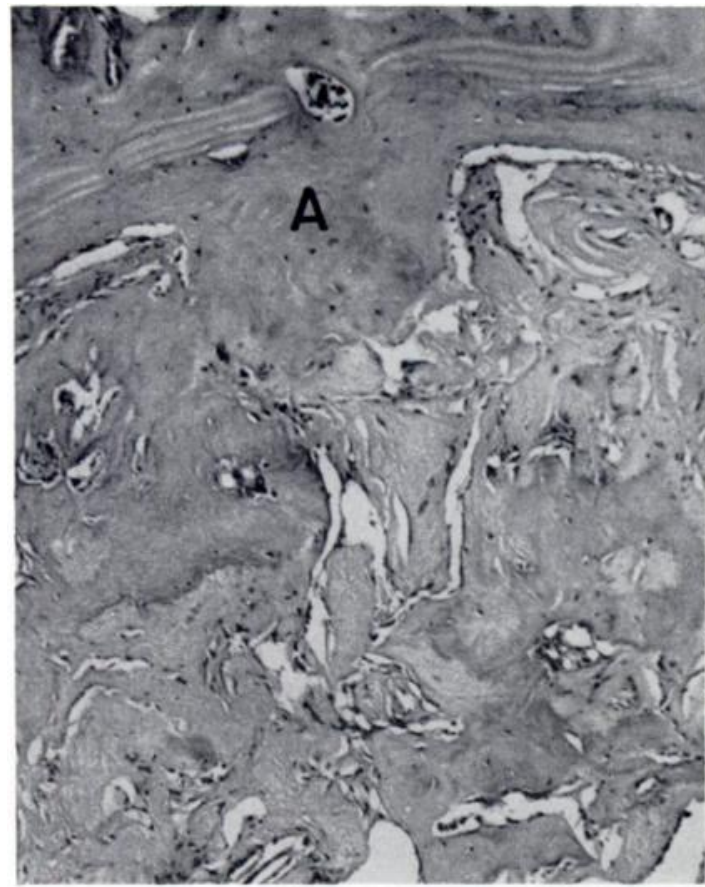

FIG. 3

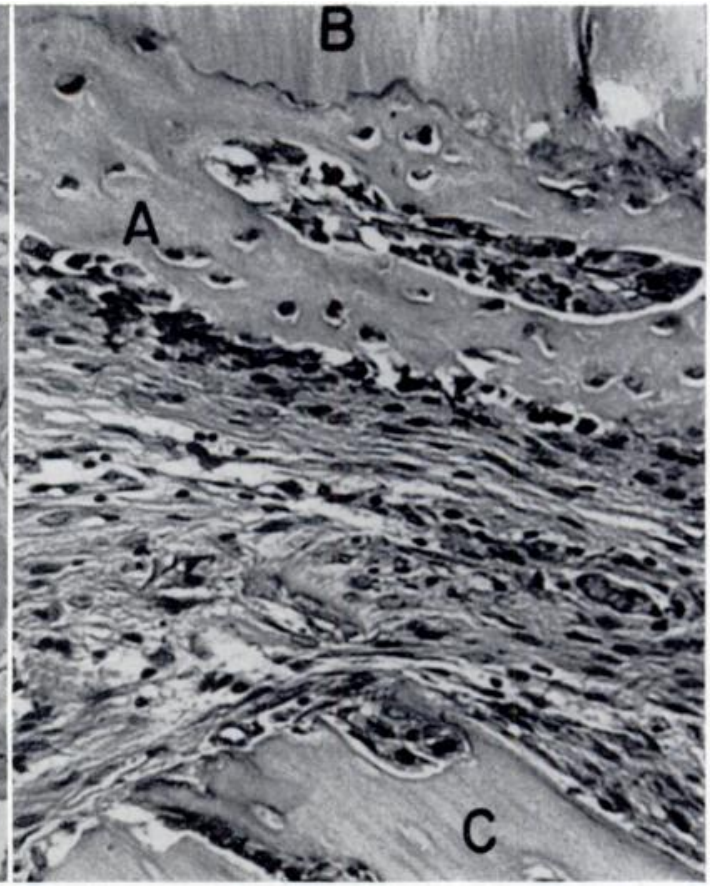

FIG. 4

Figure 3-Gelfoam-chondroitin sulphate-implanted defect after seven weeks. A small amount of new bone formation may be observed (A) attached to the margin of the wound. (Haematoxylin and eosin, $\times 100$.) Figure 4-Demineralised bone-implanted defect, after one week. Areas of new bone (A) and osteoblastic activity are seen extending from the host bone (B) into the defect. The implant material is seen at $\mathrm{C}$. (Haematoxylin and eosin, $\therefore 450$.)

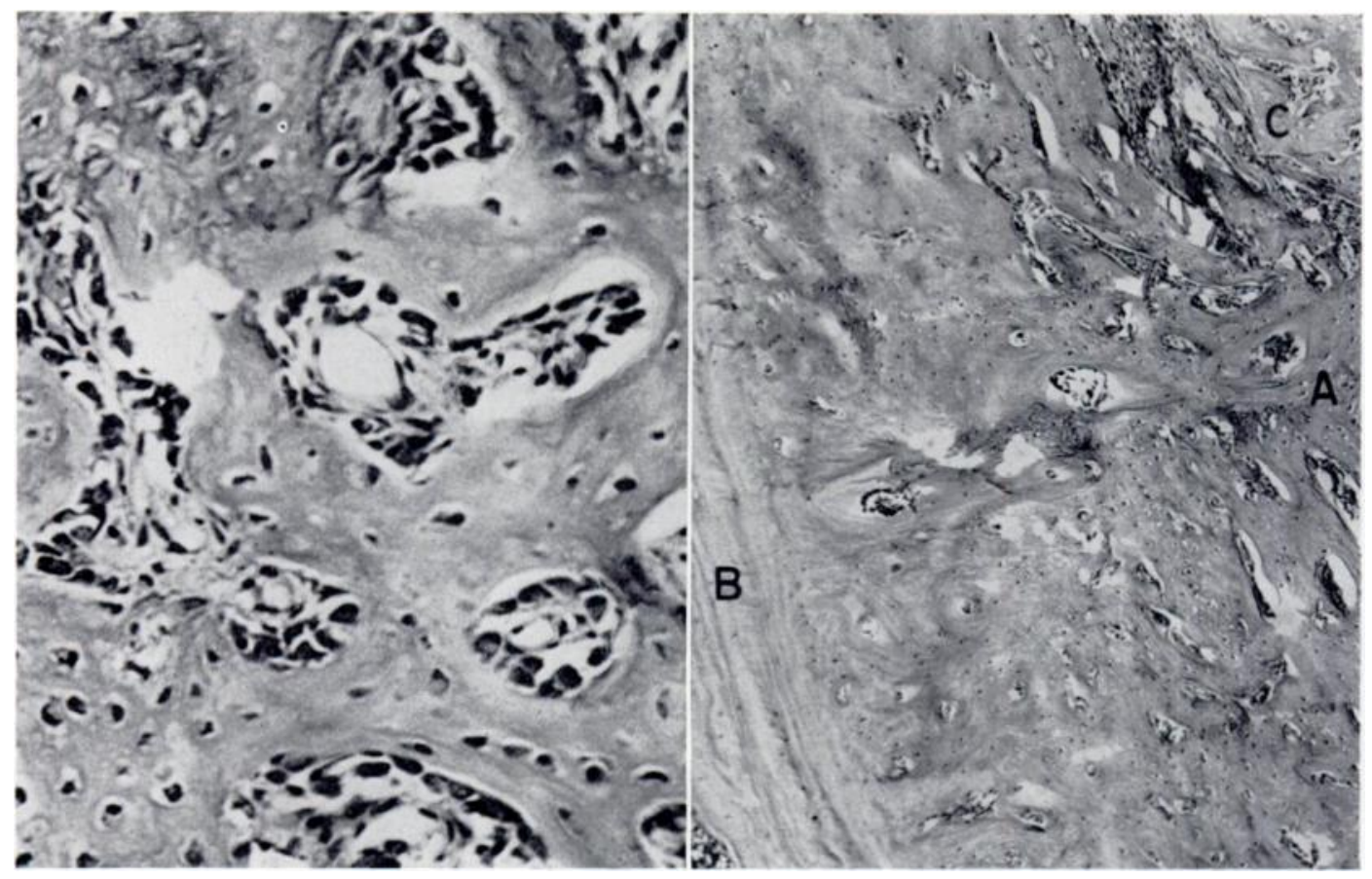

Fig. 5

FIG. 6

Figure 5-Demineralised bone-implanted defect between the second and fifth weeks after implantation. Extensive osteoblastic activity is present. (Haematoxylin and eosin, 450.) Figure 6-Demineralised boneimplanted defect after six weeks. The newly formed bone is becoming more organised (A) and in some areas is touching the implant material (C). The host bone is at B. (Haematoxylin and eosin, $: 75$.)

VOL. 44 B, NO. 3, AUGUST 1962 
Controls-At best, only traces of repair were seen in the unimplanted defects nine weeks following operation. Histological observation showed that, except for a few trabeculae of new bone extending into the wound area from the margin most of the defect was occupied by dense fibrous connective tissue (Fig. 1).

Gelfoam and Gelfoam-chondroitin sulphate-Little repair of the defect was found seven weeks after the implantation of Gelfoam into the calvaria. The wound was occupied by a mass of fibrous connective tissue with a trace of osteoblastic activity immediately adjacent to the margin of the defect (Fig. 2). In those animals which received Gelfoam treated with chondroitin sulphate there was more new bone formation along the margin of the host bone seven weeks after implantation. Even in these, however, the development of trabeculae of new bone in the area of the defect was not far advanced (Fig. 3).

Fresh homogenous bone and demineralised bone-The use of fresh homogenous (normal or rachitic) or demineralised bone as implant materials produced a series of morphological events which were similar. The following description is, therefore, applicable to all defects in which these materials were used.

One week after the operation there was a slight resorption of the bone in some portions of the margin of the wound. At the same time osteoblastic activity with trabeculae of new bone extending from the margin of the host bone into the area of the defect was observed (Fig. 4). There was no incorporation of the implant material into either the host bone or the new trabeculae of bone. Most of the wound was occupied by a mass of moderately dense fibrous connective tissue containing fibroblasts. The area was well vascularised, and a very slight foreign body reaction was observed.

From the second to the fifth week following implantation there was extensive osteoblastic activity in the area of the defect. Many trabeculae of newly formed bone extended inward toward the centre of the wound from the margin of the host bone (Fig. 5). In several instances these trabeculae adjoined and incorporated the implant material into the developing spongy network. Vascularisation of the area was more extensive. Reaction of the surrounding tissue to the presence of the implant material was negligible during this period of time.

The sixth week after implantation was characterised by an increasing vascularisation of the defect and a consolidation of the new trabeculae of bone (Fig. 6). It was not until nine weeks had elapsed, however, that the entire defect was healed with compact bone (Fig. 7).

Demineralised bone-chondroitin sulphate-Both tibiae and skull implants (demineralised and treated with 1 per cent chondroitin sulphate) produced a similar repair of the defects. One week after implantation of the material new bone grew from the margin of the wound into the well-vascularised area of fibrous connective tissue (Fig. 8). Bone formation proceeded rapidly between the second and fifth weeks after the operation. Many bony elements were seen extending from the margin of the host bone to fragments of the implanted material. Often these new trabeculae of bone were found to be partially surrounding the implants (Fig. 9). Osteoblastic activity was extensive in these areas.

Complete repair of the defect occurred six weeks after the operation. The wound was completely closed with newly formed compact bone (Fig. 10).

Figure 11 is a radiograph of an implanted rat calvarium six weeks after operation. The right side-which contained demineralised bone treated with 1 per cent chondroitin sulphateshows the most repair of the defect. The left side-which received the untreated demineralised bone-shows only partial healing.

Collagen- $\mathbf{N a C l}-$ One week after the operation only slight changes were seen in the wounds in which acid-soluble collagen reconstituted with $\mathrm{NaCl}$ had been implanted. Apart from a deeper eosinophilia of a few areas and the presence of a few nests of cartilage-like cells, the implant area was filled with a mass of dense fibrous connective tissue (Fig. 12). Eight weeks after implantation a moderate amount of new bone formation was found in the area of the defect, but organisation of this new bone into compact bone had not yet occurred (Fig. 13). 


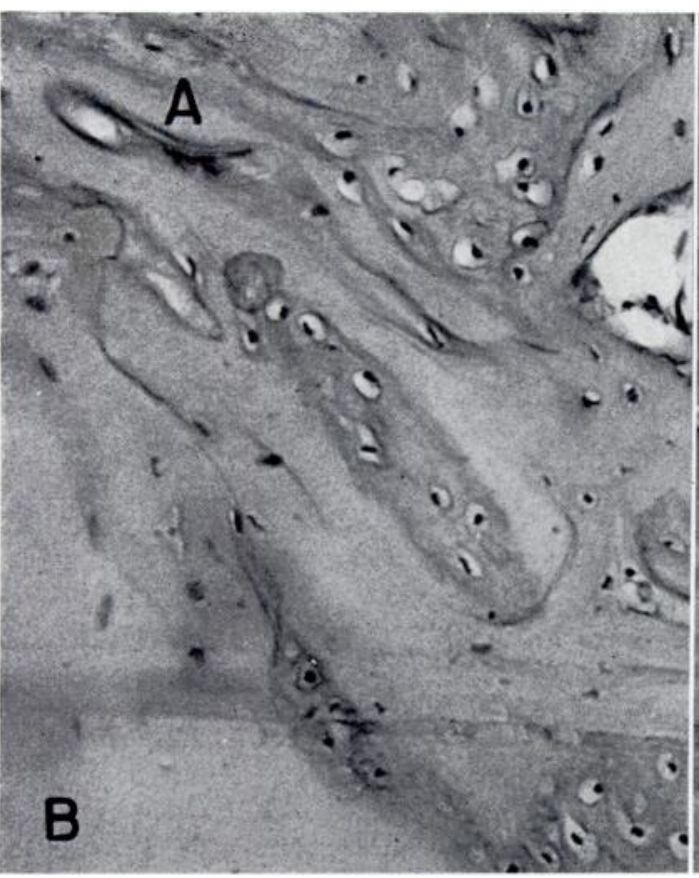

FIG. 7

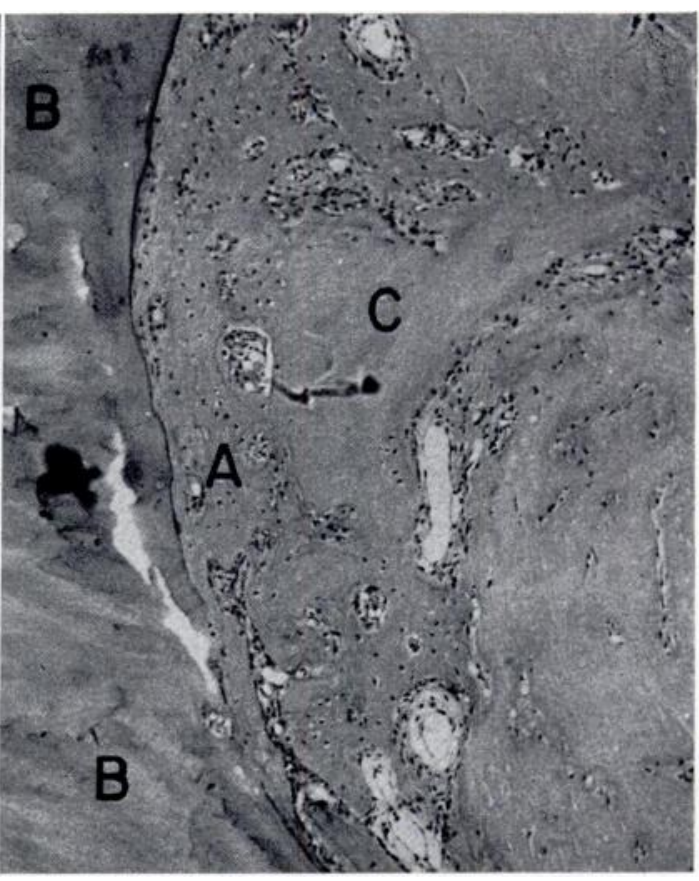

FIG. 8

Figure 7-Demineralised bone-implanted defect after nine weeks. The defect is filled in with newly formed compact bone (A) attached to the margin of the wound (B). (Haematoxylin and eosin, $\times 450$.) Figure 8Demineralised bone-chondroitin sulphate-implanted defect, after one week. Trabeculae of new bone (A) are seen extending from the margin of the defect $(B)$ into the area of the wound, and, in places, partially surround the implant material $(C)$. The area is well vascularised. (Haematoxylin and eosin, $\times 100$.)

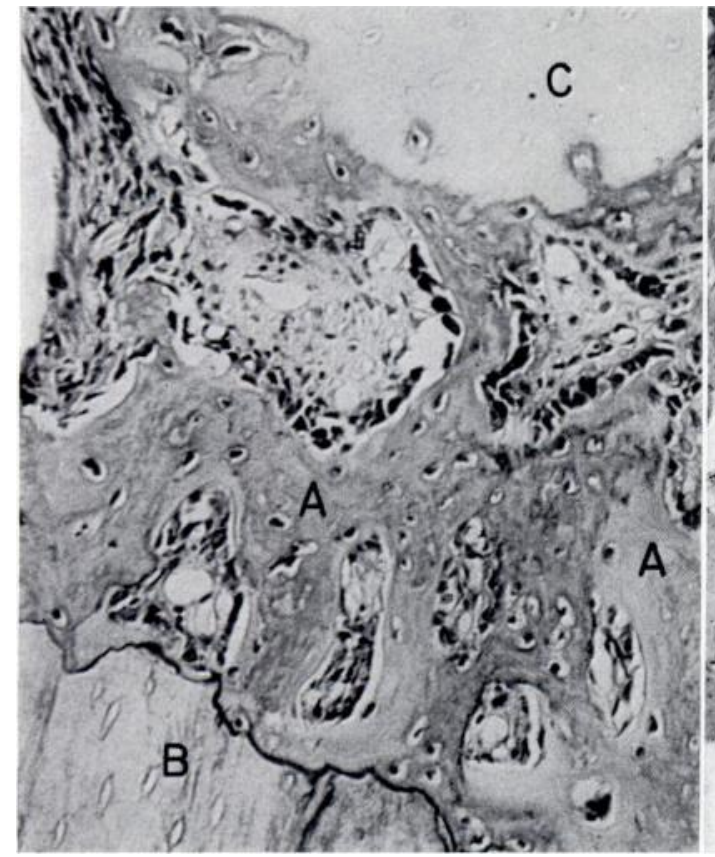

FIG. 9

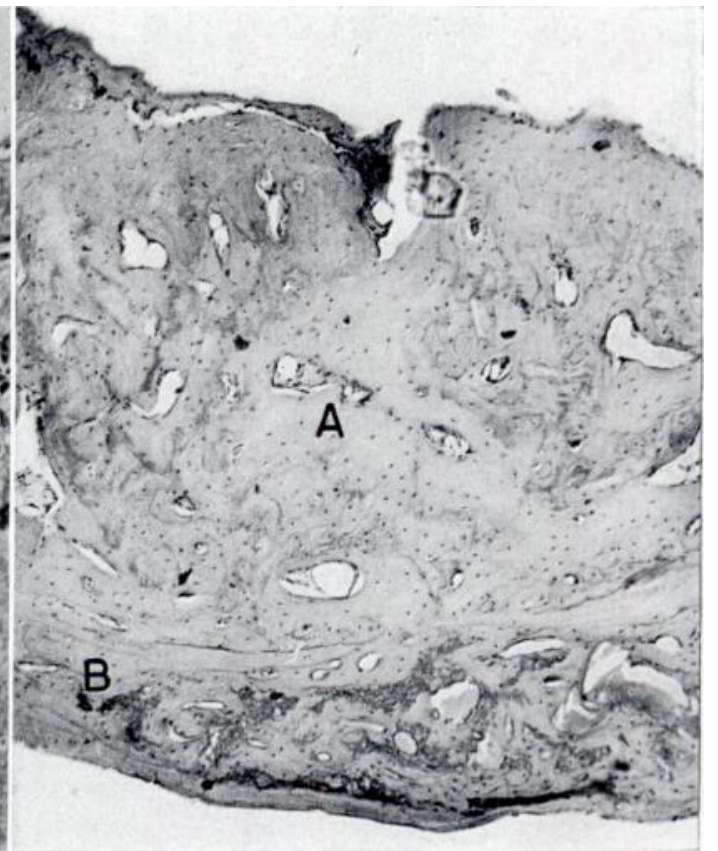

FIG. 10

Figure 9-Demineralised bone-chondroitin sulphate-implanted defect between the second and fifth weeks after implantation. There is extensive osteoblastic activity with trabeculae of new bone (A) extending from the margin of the defect (B) up to and partially surrounding the implant material (C). (Haematoxylin and eosin, $\times 335$.) Figure 10-Demineralised bone-chondroitin sulphate-implanted defect after six weeks. The portion of the defect shown here has been healed by compact bone (A) which is fused to the margin of the host bone (B). (Haematoxylin and eosin, $\times 75$.)

VOL. 44 B, NO. 3, AUGUST 1962 
Collagen-chondroitin sulphate-When acid-soluble collagen reconstituted with 1 per cent chondroitin sulphate was used as the implant material, a few areas of increased eosinophilia were seen in the defect one week after operation (Fig. 14); in fact, the histological picture appeared quite similar to that seen with collagen- $\mathrm{NaCl}$ at the same time in the healing period. After eight weeks the resemblance ended, because the wound was completely healed with new compact bone (Fig. 15), while only moderate repair was effected with collagen- $\mathrm{NaCl}$ (Fig. 13).

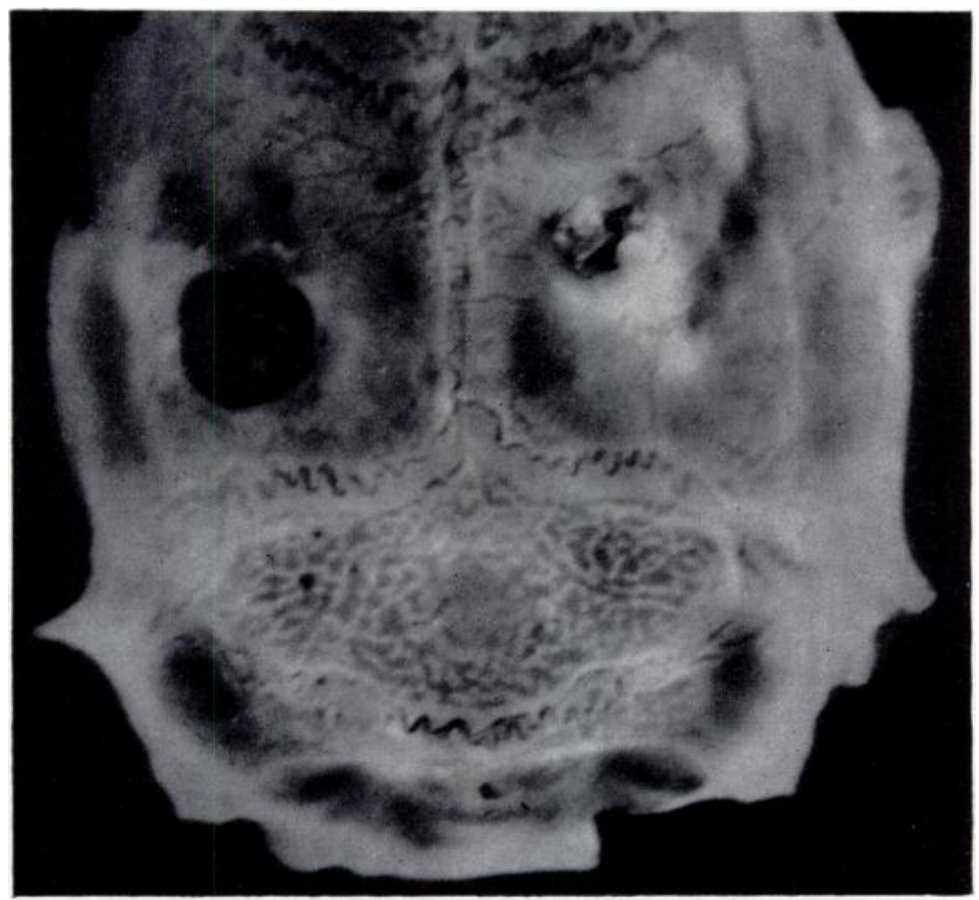

Fig. 11

Radiograph of a rat calvarium six weeks after implantation. The right side contained demineralised bone treated with chondroitin sulphate, and is almost entirely radio-opaque. The left side contained demineralised bone alone, and shows only partial healing. $(\times 7$.

\section{DISCUSSION}

It is evident in these studies that chondroitin sulphate treatment accelerates the rate of new bone formation promoted by demineralised bone and reconstituted acid-soluble collagen (Table III). The observation that demineralised bone by itself promotes bone repair confirms the findings of Ray and Holloway (1957), Miller (1890) and Senn (1889). In addition, we have shown that $\mathrm{NaCl}$-reconstituted acid-soluble collagen can also promote bone repair, but at a slower rate.

The healing seen with chondroitin sulphate-treated demineralised bone at the end of six weeks was the greatest $(+++++)$. This degree of bone repair was reached at the end of nine weeks using demineralised bone alone. With chondroitin sulphate-reconstituted acidsoluble collagen, a ++ degree of repair was reached at the end of three weeks, and +++++ healing was obtained at the end of eight weeks. In the case of $\mathrm{NaCl}$-reconstituted acid-soluble collagen only ++ healing was found at the end of eight weeks, and at no time was the greatest possible repair $(+++++)$ observed during the experimental period.

With Gelfoam only + repair was found at the end of seven weeks of observation. Treatment of the Gelfoam with chondroitin sulphate resulted in a somewhat increased repair $(++)$ at the end of this period. It is possible that with a longer period of observation an 


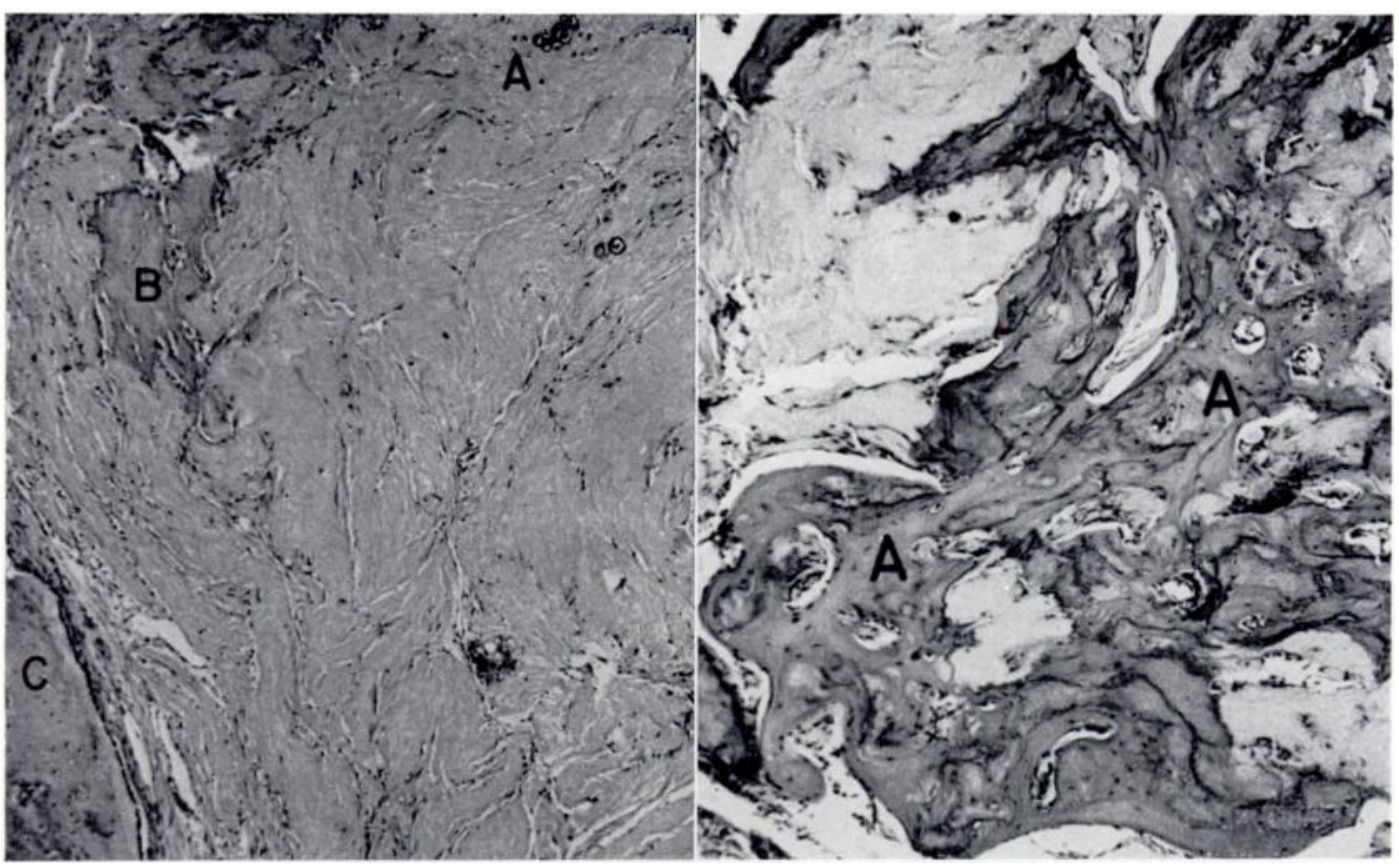

FIG. 12

FiG. 13

Figure 12-Acid soluble collagen-sodium chloride-implanted defect after one week. It is filled in with fibrous connective tissue. Apart from a few cartilage-like cells (A) and a few areas of deeper eosinophilia (B), no trabeculae of bone are seen growing from the margin of the wound $(C)$. (Haematoxylin and eosin, 75 .) Figure 13-Acid-soluble collagen-sodium chloride-implanted defect after eight weeks. A moderate amount of new bone formation $(A)$ is present in the area of the wound. (Haematoxylin and eosin, $x 100$.)

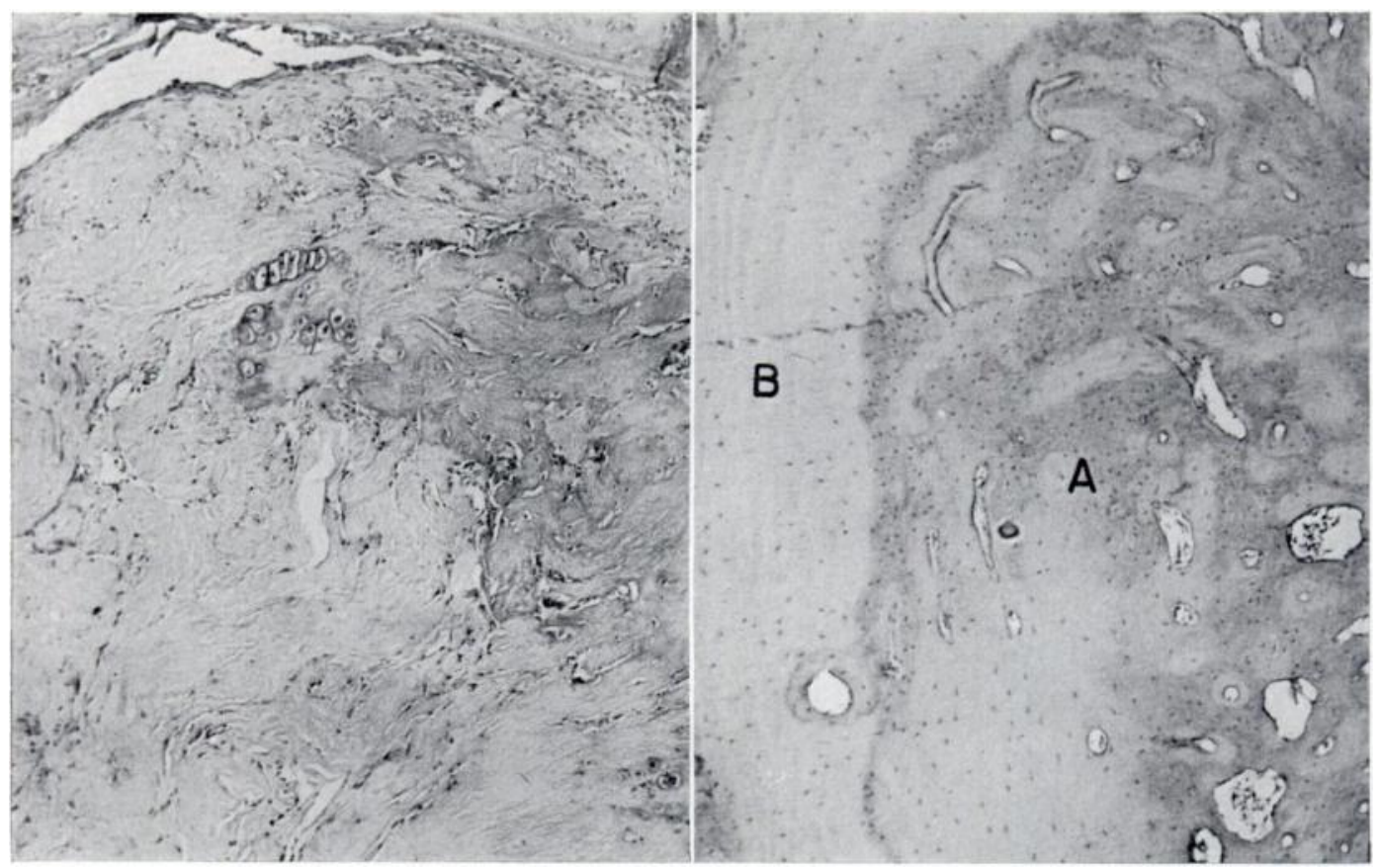

FIG. 14

FIG. 15

Figure 14-Acid-soluble collagen-chondroitin sulphate-implanted defect after one week. The area of the wound greatly resembles that of Figure 12. As yet there is no substantial formation of new bone. (Haematoxylin and eosin, $\times 75$.) Figure 15-Acid-soluble collagen-chondroitin sulphate-implanted defect after eight weeks. The wound is completely healed with new compact bone (A). The margin of the host bone is at $\mathrm{B}$. (Haematoxylin VOL. 44 B, NO. 3, AUGUST 1962 and eosin, $\times 75$.) 
increased difference in the rate of repair would be noted with the chondroitin sulphate-treated Gelfoam. But since the total amount of repair was less in comparison to chondroitin sulphatetreated collagen or demineralised bone, we did not extend these investigations.

The untreated controls showed only + healing after nine weeks. This is less than was found with any of the implant materials.

The bone repair found with fresh homogenous bone was of the same magnitude as that found with untreated demineralised bone. Thus, chondroitin sulphate-treated demineralised bone promoted a decisively faster rate of bone repair than any other substance employed in these studies.

The mechanism by which demineralised bone or collagen implants, treated with chondroitin sulphate, accelerate the repair of a bony defect is not clear. The hypothesis that bone contains an extractable substance, or substances, capable of inducing new bone formation has been put forth by several investigators (Bertelsen 1944; Levander and Willestaedt 1946; Willestaedt, Levander and Hult 1950; Hellstadius 1955; Moss 1958, 1960). This "inductor" factor may be a mucopolysaccharide, such as chondroitin sulphate (Moss 1958) or a proteinmucopolysaccharide complex (Moss 1960). Indeed, recent evidence (Bruckschen 1959) suggests that mucopolysaccharides such as chondroitin sulphate and hyaluronic acid can contribute to the formation of new bone in the guinea-pig.

It is known that the subcutaneous injection of carrageenin (a mucopolysaccharide extracted from Irish moss) into the guinea-pig will lead to the formation of a collagenous mass of new connective tissue (Robertson and Schwartz 1953, Williams 1957, Jackson 1957, Slack 1957, 1958, Williams 1959). Does chondroitin sulphate-or a complex of chondroitin sulphate-act in a similar manner in the formation of bone? In the opinion of Dziewiatkowski (1960), chondroitin sulphate may play a part in new bone formation. He found that mucopolysaccharides were synthesised at an increased rate in hypertrophic epiphysial cartilage. This mucopolysaccharide was then secreted into the matrix and participated in changes that made it possible for the bone to mineralise. The chondroitin sulphate in the matrix is used in the formation of metaphysial bone (Dziewiatkowski, Bronner, DiFerrante and Archibald 1957). This statement also applies to intramembranous bone and bone formed in Haversian systems where the osteoblast occupies a role analogous to the role of hypertrophic cartilage. A similar function for mucopolysaccharides has been implied in the studies of Ponlot (1960).

Our knowledge of the role of chondroitin sulphate in the formation of bone is incomplete and requires further investigation. We believe, however, that the present studies indicate a method for accelerating the repair of bony defects which may eventually prove to be valuable in the field of orthopaedic surgery.

\section{SUMMARY}

1. A study has been made of the repair of bony defects in the calvaria of albino rats.

2. An accelerated rate of bone repair was observed in experimental defects into which chondroitin sulphate-treated demineralised bone was implanted.

3. Acid-soluble collagen reconstituted with chondroitin sulphate was also more effective as an implant than was acid-soluble collagen reconstituted with sodium chloride.

4. It is concluded from these studies that chondroitin sulphate treatment accelerated the rate of new bone formation induced by demineralised bone, by reconstituted acid-soluble collagen, and to a lesser extent by Gelfoam. It was also found that demineralised bone and fresh homogenous bone promoted bone repair, but that chondroitin sulphate-treated demineralised bone promoted the most rapid rate of bone repair among the substances tested.

5. The possible role of chondroitin sulphate in bone formation is discussed.

We are grateful to Dr Leroy Lavine of the Department of Orthopaedics, State University of New York, Downstate Medical Center, for his participation in the early phases of this work and for his help in standardising the surgical techniques employed. 
This research was supported in part by the United States Air Force under contract AF(657)-229 monitored by the School of Aviation Medicine, U.S.A.F., Randolph Air Force Base, Texas; by the National Institute of Dental Research, N.I.H., Public Health Service Grant D-55; and the Office of Naval Research Project NR 105-025. A preliminary report of this work was presented before the International Congress on Clinical Chemistry, Stockholm, Sweden, August 19-23, 1957. (Sobel, Burger and Deane 1957.)

Presented before the American Society of Biological Chemists, Chicago, Illinois, April 11-15, 1960. (Burger, Sherman and Sobel 1960.)

\section{REFERENCES}

Bertelsen, A. (1944): Experimental Investigations into Post-Foetal Osteogenesis. Acta Orthopaedica Scandinavica, 15, 139.

Bills, C. E., Honeywell, E. M., Wirick, A. M., and Nussmeier, M. (1931): A Critique of the Line Test for Vitamin D. Journal of Biological Chemistry, 90, 619.

BRUCKSCHEN, E. (1959): Histologische Ergebnisse nach Implantation von Hyaluronsaure und Chondroitinschwefelsaure. Naturwissenschaften, 46, 671.

Burger, M., Lavine, L. S., Deane, B. C., and Sobel, A. E. (1957): Calcification XIX. Calcification of Transplanted Rachitic Bone. Proceedings of the Society for Experimental Biology and Medicine, 96, 147.

Burger, M., Sherman, B. S., and Sobel, A. E. (1960): Acceleration of Osteogenesis by Chondroitin SulfateTreated Demineralized Bone. Federation Proceedings, 19, 335.

Dziewiatkowski, D. D. (1960): Personal communication.

Dziewiatkowski, D. D., Bronner, F., Diferrante, N., and Archibald, R. M. (1957): Some Aspects of the Metabolism of Sulfate- $S^{35}$ and Calcium ${ }^{45}$ in the Metaphyses of Immature Rats. Influence of $\beta$-Estradiol Benzoate. Journal of Biophysical and Biochemical Cytology, 3, 151.

Hellstadius, A. (1955): Studies on Osteogenesis around Autoplastic Bony Transplants in Bony Defects. Acta Orthopaedica Scandinavica, 24, 278.

JACkson, D. S. (1957): Connective Tissue Growth Stimulated by Carrageenin. I. The Formation and Removal of Collagen. Biochemical Journal, 65, 277.

Levander, G., and Willestaedt, H. (1946): Alcohol-Soluble Osteogenetic Substance from Bone Marrow. Nature, 157, 587.

Miller, A. G. (1890): A Case of Bone Grafting with Decalcified Bone Chips; Remarks. Lancet, ii, 618.

Moss, M. L. (1958): Extraction of an Osteogenic Inductor Factor from Bone. Science, 127, 755.

Moss, M. L. (1960): Experimental Induction of Osteogenesis. Calcification in Biological Systems. Edited by Sognnaes, R. F., p. 323. Washington, D.C.: American Association for the Advancement of Science.

Ponlot, R. (1960): Le radiocalcium dans l'étude des os. Brussels: Editions Arscio.

Ray, R. D., and Holloway, J. A. (1957): Bone Implants. Preliminary Report of an Experimental Study. Journal of Bone and Joint Surgery, 39-A, 1,119.

Robertson, W. van B., and Schwartz, B. (1953): Ascorbic Acid and the Formation of Collagen. Journal of Biological Chemistry, 201, 689.

Senn, N. (1889): On the Healing of Aseptic Bone Cavities by Implantation of Antiseptic Decalcified Bone. American Journal of the Medical Sciences, 98, 219.

Slack, H. G. B. (1957): Connective Tissue Growth Stimulated by Carrageenin II. The Metabolism of Sulphated Polysaccharides. Biochemical Journal, 65, 459.

Slack, H. G. B. (1958): Connective Tissue Growth Stimulated by Carrageenin III. The Nature and Amount of Polysaccharide Produced in Normal and Scorbutic Guinea Pigs and the Metabolism of a Chondroitin Sulphuric Acid Fraction. Biochemical Journal, 69, 125.

Sobel, A. E. (1961): Remineralization of Bones and Teeth. International Dental Journal, 11, 363.

Sobel, A. E., and Burger, M. (1954): Calcification XIV. Investigations of the Role of Chondroitin Sulfate in the Calcifying Mechanism. Proceedings of the Society for Experimental Biology and Medicine, 87, 7.

Sobel, A. E., Burger, M., and Deane, B. C. (1957): Studies of the Mechanism Responsible for Initiation of Mineralization. Scandinavian Journal of Clinical and Laboratory Investigation, 10, Supplementum 31, 309.

Sobel, A. E., Burger, M., and LAvine, L. S. (1960): Calcification of the Epiphyseal Cartilage of Demineralized Bone Sections. Abstracts 4th International Congress of Biochemistry, Vienna, Austria, Sept. 1-6, 1958, Section 12, Number 12-74, p. 159. Oxford, London, New York, Paris: Pergamon Press.

Sobel, A. E., Burger, M., and Nobel, S. (1960): Mechanism of Nuclei Formation in Mineralizing Tissues. Clinical Orthopaedics, 17, 103.

Willestaedt, H., Levander, G., and Hult, I. (1950): Studies in Osteogenesis. Acta Orthopaedica Scandinavica, $19,419$.

Williams, G. (1957): A Histological Study of the Connective Tissue Reaction to Carrageenin. Journal of Pathology and Bacteriology, 73, 557.

Williams, G. (1959): Some Histological Aspects of Connective Tissue Metabolism in Acute Scorbutus. British Journal of Experimental Pathology, 40, 176.

Vol. 44 B, No. 3, AUGUST 1962 